\title{
Trabeculectomy: a review and 4-year follow-up
}

\author{
A. A. ZAIDI \\ From the Manchester Royal Eye Hospital
}

SUMMARY Since the first attempt at glaucoma surgery in 1830 many surgical procedures have been devised and adopted depending on the understanding of the aetiology and pathogenesis of the disease. Trabeculectomy, the most recent drainage procedure for glaucoma, has become a widely used, effective, and safe method, particularly for chronic simple glaucoma. Up to 4 years' follow-up of 66 eyes ( 55 patients) is reported. The findings at 6 months, 1 year, 2 years, 3 years, and 4 years were in agreement with previous reports by other authors. The main postoperative complication was transient hyphaema. Of the total number of eyes, 7 needed miotic drops and 5 required further surgical procedures to control the intraocular pressure.

Since Cairns described trabeculectomy, ${ }^{1}$ it has been adopted by many ophthalmic surgeons, as it is a relatively effective and safe drainage procedure, particularly for chronic simple glaucoma.

The previously described drainage procedures of anterior sclerotomy, partial sclerotomy and iridectomy, cyclodialysis, iridencleisis, corneoscleral trephine and iridectomy, and sclerocautery have all been found to be unsatisfactory for some reason or other, among which the following are the commonest.

(1) Loss of anterior chamber. The anterior chamber was lost or became very shallow during surgery or postoperatively, with resulting complications such as anterior synechiae formation, secondary glaucoma, and cataract.

(2) Infection. Owing to the superficial situation of the bleb (being covered only by the conjunctiva and Tenon's capsule) infection was the most feared complication. Some eyes were lost as a result of intraocular spread of the infection, resulting in panophthalmitis.

(3) Large bleb. In some eyes the bleb became so large that it not only became cosmetically embarrassing but also covered the cornea and the pupil, causing visual disturbance.

(4) Malignant glaucoma. Some eyes developed malignant glaucoma soon after surgery. This was due to the forward displacement of the vitreous and the iris-lens diaphragm obstructing the pupil and the outflow of the aqueous humour.

Correspondence to A. A. Zaidi, FRCS, Rotherham District General Hospital, Moorgate Road, Oakwood, Rotherham S60 2UD.
(5) Closure of the fistula. This was the main longterm complication and occurred as a result of subconjunctival fibrosis. This is commonest in Africans. ${ }^{2}$

Because no operation was free of complications the attention of researchers was directed at the trabecular meshwork where the obstruction to outflow was thought to lie. Thus Redmond Smith described trabeculotomy ${ }^{3}$ and was followed by Allen and Burian ${ }^{4}$, and Harms and Dannheim. ${ }^{5}$ Krasnov described sinusotomy ${ }^{6}$ and finally Cairns described trabeculectomy. ${ }^{1}$ Cairns's original method was modified by Watson ${ }^{7}$ and has since then been adopted by many ophthalmic surgeons with a few minor surgical modifications. Most authors agree that the mechanism of drainage following trabeculectomy is by the formation of a fistula between the anterior chamber and the subconjunctival space.

Several reports have described the results of trabeculectomy, which are promising in the control of raised intraocular pressure and have few complications. Thus Thyer and Wilson ${ }^{8}$ reported encouraging results, and Ridgway et al. ${ }^{9}$ reported a success rate of $92 \%$. Ridgway ${ }^{10}$ reported further successes with this operation.

Negroes respond poorly to filtering surgical procedures. Welsh ${ }^{2}$ concluded that failure of fistula formation is due mainly to overgrowth of the external scleral fistula by fibrous tissue derived from the sclera and Tenon's capsule. But with trabeculectomy Welsh ${ }^{11}$ reported a success rate of $65 \%$ in Negroes and Freedman et al. ${ }^{12} 86 \%$ in black Americans.

Tord Jerndal and Viiu Kriisa ${ }^{13}$ reported control of intraocular pressure in 42 out of 52 cases $(80 \cdot 76 \%)$ 
Table 1 Pre- and post-operative intraocular pressure in $\mathrm{mmHg}$

\begin{tabular}{|c|c|c|c|c|c|c|c|}
\hline \multirow{3}{*}{$\begin{array}{l}\text { Level of } \\
\text { IOP }\end{array}$} & \multicolumn{7}{|l|}{ No. of eyes } \\
\hline & \multirow[t]{2}{*}{ Before op. } & \multicolumn{2}{|c|}{ After op. } & \multirow[b]{2}{*}{$\begin{array}{l}1 \\
\text { year }\end{array}$} & \multirow[b]{2}{*}{$\begin{array}{l}2 \\
\text { years }\end{array}$} & \multirow[b]{2}{*}{$\begin{array}{l}3 \\
\text { years }\end{array}$} & \multirow[b]{2}{*}{$\begin{array}{l}4 \\
\text { years }\end{array}$} \\
\hline & & $1 / 12$ & $6 / 12$ & & & & \\
\hline$<21$ & 0 & 56 & 54 & 46 & 45 & 37 & 16 \\
\hline $21-30$ & 44 & 7 & 8 & 9 & 5 & 3 & 4 \\
\hline $31-40$ & 18 & 2 & 4 & 2 & 0 & 1 & \\
\hline $41-50$ & 3 & 1 & 0 & 0 & 1 & 1 & \\
\hline $51-60$ & 1 & 0 & 0 & 0 & 0 & 0 & \\
\hline Total & 66 & 66 & 66 & 57 & 51 & 42 & 20 \\
\hline
\end{tabular}

Age range: $20-83$ years. Mean age: 50 years.

of pseudoexfoliative glaucoma. Sandford Smith ${ }^{14}$ came to the conclusion that trabeculectomy produced fewer complications but otherwise there was little difference in the control of intraocular pressure. A few cases of combined trabeculectomy and cataract extractions have been reported, but without any conclusive results as the cases are too few. ${ }^{8}$

The purpose of this paper is to report the follow-up of 66 eyes (55 patients) up to 4 years after trabeculectomy for uncontrolled chronic simple glaucoma, except for 3 eyes, 1 with chronic closed-angle glaucoma and 2 with neovascular glaucoma (central retinal vein occlusion).

\section{Material and methods}

Trabeculectomy was performed on 66 eyes (55 patients) between the end of 1973 and the end of 1977 in 1 unit of the Manchester Royal Eye Hospital. All the eyes except 3 showed chronic simple glaucoma; 2 had neovascular glaucoma (following central retinal vein occlusion), and 1 was a case of chronic closed-angle glaucoma.

All 66 eyes showed progressive field loss despite maximum medical treatment with local and systemic therapy-pilocarpine $4 \% 4$ times a day, adrenaline
$1 \%$ twice a day where indicated, and acetazolamide $250 \mathrm{mg}$ orally 4 times a day. The presence or absence of lens opacities was noted preoperatively to determine the number of eyes developing lens opacities as a result of trabeculectomy. Fourteen eyes had lens opacities before surgery. The ages of the patients varied from 18 to 83 years, mean 50 (Table 1). The total number of patients shown is 55 and not 66 because 11 had trabeculectomy on both eyes.

The criteria for operation were progression of field defect and raised intraocular pressure above $21 \mathrm{mmHg}$ despite maximum medical treatment. Patients for operation were admitted to the ward for glaucoma assessment 1 week prior to surgery. This was to ascertain that the intraocular pressure remained raised above $21 \mathrm{mmHg}$ despite instillation of drops and administration of tablets by trained staff.

Intraocular pressures were recorded twice a day by applanation tonometry. The immediate preoperative intraocular pressures were recorded and divided into 4 groups (Table 1): (1) $21-30 \mathrm{mmHg}$, (2) $31-40 \mathrm{mmHg}$, (3) $41-50 \mathrm{mmHg}$, (4) $51-60$ mmHg. Visual acuity (Snellen's chart) was also recorded before surgery and the patients were divided into 3 groups (Table 2): (1) 6/4-6/12, (2) $6 / 18-6 / 60$, (3) Less than $6 / 60$. Intraocular pressures and visual acuity were recorded at 1 month, 6 months, 1 year, 2 years, 3 years, and 4 years after the operation and compared with the preoperative findings (Tables 1 and 2). Any lens opacities were also recorded. Immediate and late complications were noted.

It will be noticed from Tables 2 and 3 that from the sixth month the end of the 4 years the total number of eyes becomes less. This is because the study began in 1973 and cases are recorded from then until the end of 1977, so not all eyes were subjected to the 4-year follow-up.

\section{SURGICAL TECHNIQUE}

Most operations were carried out under a local anaesthetic by the consultant or senior registrar,

Table 2 Pre- and post-operative visual acuity (Snellen's chart)

\begin{tabular}{|c|c|c|c|c|c|c|c|c|c|c|c|c|}
\hline \multirow{3}{*}{ Visual acuity } & \multicolumn{12}{|c|}{ No. of eyes and percentage } \\
\hline & \multicolumn{2}{|c|}{ Before op. } & \multicolumn{2}{|c|}{$\begin{array}{l}\text { After op. } \\
6 / 12\end{array}$} & \multicolumn{2}{|l|}{1 year } & \multicolumn{2}{|l|}{2 years } & \multicolumn{2}{|l|}{3 years } & \multicolumn{2}{|l|}{4 years } \\
\hline & $\begin{array}{l}\text { No. of } \\
\text { eyes }\end{array}$ & $(\%)$ & $\begin{array}{l}\text { No. of } \\
\text { eyes }\end{array}$ & $(\%)$ & $\begin{array}{l}\text { No. of } \\
\text { eyes }\end{array}$ & $(\%)$ & $\begin{array}{l}\text { No. of } \\
\text { eyes }\end{array}$ & $(\%)$ & $\begin{array}{l}\text { No. of } \\
\text { eyes }\end{array}$ & $(\%)$ & $\begin{array}{l}\text { No. of } \\
\text { eyes }\end{array}$ & $(\%)$ \\
\hline $6 / 4-6 / 12$ & 36 & $(54 \cdot 5)$ & 26 & $(39 \cdot 3)$ & 22 & $(36 \cdot 5)$ & 17 & $(33 \cdot 3)$ & 14 & $(33 \cdot 3)$ & 5 & (25) \\
\hline $6 / 18-6 / 60$ & 16 & $(24 \cdot 25)$ & 27 & (41) & 20 & $(35.0)$ & 18 & $(35 \cdot 2)$ & 13 & $(30 \cdot 9)$ & 7 & (35) \\
\hline Less than $6 / 60$ & 14 & $(21 \cdot 25)$ & 13 & $(19 \cdot 6)$ & 15 & $(26 \cdot 3)$ & 16 & $(31 \cdot 3)$ & 15 & $(35.9)$ & 8 & (40) \\
\hline
\end{tabular}


Table 3 Percentage of eyes with intraocular pressure less than $21 \mathrm{mmHg}$ after surgery

\begin{tabular}{llll}
\hline $\begin{array}{l}\text { Postoperative } \\
\text { duration }\end{array}$ & $\begin{array}{l}\text { No. of eyes with } \\
\text { IOP }<21 \text { mm Hg }\end{array}$ & Total eyes & $\%$ \\
\hline One month & 56 & 66 & $84 \cdot 4$ \\
Six months & 54 & 66 & $81 \cdot 8$ \\
One year & 46 & 57 & $80 \cdot 7$ \\
Two years & 45 & 51 & $88 \cdot 1$ \\
Three years & 37 & 42 & 88.9 \\
Four years & 16 & 20 & 80.0 \\
\hline
\end{tabular}

except on 2 eyes which were operated on by the registrar. Promethazine $25 \mathrm{mg}$ was given intramuscularly as premedication $1 \frac{1}{2}$ hours before surgery to the patients to be operated on under a local anaesthetic. All eyes were operated on with the aid of a surgical microscope.

A 6-7 mm limbal based conjunctival flap was turned down over the cornea and the limbus was cleared of Tenon's capsule. A lamellar scleral trapdoor $4 \mathrm{~mm}$ wide and extending $5 \mathrm{~mm}$ posteriorly from the limbus was dissected forwards to hinge anteriorly at the 12 o'clock position at the limbus. The bed of this trapdoor now consists of the deep sclerotrabecular lamella, and a $4 \times 2 \mathrm{~mm}$ rectangle of this lamella was marked with a razor blade fragment, the posterior incision being made along the line of the scleral spur. The sides of this rectangle were carefully deepened until penetration occurred. The rectangle of tissue was seized with fine-toothed forceps and was excised by Vanna's scissors or by razor blade fragment. A peripheral iridectomy was performed at this stage. The scleral trapdoor was closed with two $8 / 0$ virgin silk sutures at the posterior corners. The conjunctival flap was sutured with continuous $6 / 0$ catgut.

Atropine drops and chloramphenicol ointment were instilled and the eye was padded. The same medication was used twice a day postoperatively. All eyes were dressed 24 hours later and the patients were allowed out of bed. All patients were observed postoperatively as inpatients and were discharged after a minimum of 7 days provided there were no postoperative complications.

\section{Results}

INTRAOCULAR PRESSURE

Six months after surgery the intraocular pressure was found to be less than $21 \mathrm{mmHg}$ in 54 eyes $(81 \cdot 8 \%)$ (Table 1). Seven eyes needed pilocarpine $4 \% 4$ times a day to bring the intraocular pressure to below $21 \mathrm{mmHg}$. The remaining 5 eyes showed an intraocular pressure of above $22 \mathrm{mmHg}$ despite medical treatment and had to have other surgical procedures to reduce the intraocular pressure below $21 \mathrm{mmHg}$.

From Table 3 it can be seen that an intraocular pressure of less than $21 \mathrm{mmHg}$ was achieved in $84.4 \%$ of eyes after 1 month, $81.8 \%$ after 6 months, $80.7 \%$ after 1 year, $88.1 \%$ after 2 years, $88.9 \%$ after 3 years, and $80.0 \%$ after 4 years.

\section{VISUAL ACUITY}

Table 2 shows that the visual acuity gradually worsened after trabeculectomy. Thus $54.5 \%$ of eyes had visual acuity of 6/4-6/12 prior to trabeculectomy, but 4 years later only $25 \%$ of eyes retained this visual acuity. Similarly, visual acuity of $6 / 18-6 / 6$ was found in $35 \%$ of eyes 4 years after surgery as compared to that in $24.25 \%$ of eyes preoperatively. Before trabeculectomy the percentage of eyes with a visual acuity of less than $6 / 60$ was $21.25 \%$, but this had increased to $40 \% 4$ years after surgery.

\section{COMPLICATIONS}

Immediate. Hyphaema occurred in 35 eyes (53\%). Its duration varied from 1 to 21 days with an average of 7.4 days. It did not require any special treatment except rest in bed. Shallow anterior chamber was found in 7 eyes $(11.6 \%)$ lasting from 2-13 days with an average of 5.57 days. Treatment with a firm pad and bandage was found to be sufficient for the reformation of the anterior chamber. Anterior uveitis with secondary glaucoma occurred in 3 eyes $(4.5 \%)$ and was controlled by topical mydriatics, steroids, and acetazolamide orally. The anterior uveitis settled within 2-10 days with an average of 4 days, and with it the glaucoma.

Late. Lens opacities: Cataract was found in 6 eyes $(9.8 \%)$ after 6 months. These were in addition to the eyes which had cataract prior to surgery. One eye developed central retinal vein occlusion with marked drop in visual acuity. Retinal detachment occurred in 1 eye and was treated by conventional methods without success.

\section{Discussion}

INTRAOCULAR PRESSURE

After trabeculectomy 54 eyes showed intraocular pressures of less than $21 \mathrm{mmHg}$ after 1 month and were considered to be a complete success. In 7 eyes only a partial success could be claimed because the intraocular pressure of less than $21 \mathrm{mmHg}$ was not achieved with trabeculectomy alone but was obtained with miotic drops, pilocarpine $4 \%$. The remaining 5 eyes were complete failures, as they showed an intraocular pressure of more than 21 mmHg despite medical therapy. In these eyes other 
surgical procedures such as cyclodialysis, Scheie's operation, and cyclocryotherapy were carried out to reduce the intraocular pressure to an acceptable level.

VISUAL ACUITY

The major cause of gradual deterioration of visual acuity was cataract. Fourteen eyes had cataracts before they underwent trabeculectomy, while 6 eyes developed cataract postoperatively. Among the other causes were central retinal vein occlusion ( 2 eyes had CRVO before and 1 after the surgery), retinal detachment, and the glaucoma itself in uncontrolled eyes.

\section{COMPLICATIONS}

The major complication was hyphaema, which is not surprising considering the size of the wound. A significant finding was that out of the 15 eyes which showed intraocular pressure of more than $15 \mathrm{mmHg}$ after trabeculectomy 8 had postoperative hyphaema of more than 5 days' duration. It seems a fair deduction that organisation of the hyphaema may have contributed to the closure of the fistula. Immediately after trabeculectomy 10 eyes had shallow anterior chambers. This was due to excessive drainage as evidenced by large blebs.

In 6 eyes lens opacities progressed rapidly as a result of operation, with immediate reduction in visual acuity. However, visual acuity was improved with glasses in the majority of cases, while 1 patient had cataract extraction at a later date without disturbing the bleb, with reasonable improvement in visual acuity with aphakic correction. It was felt that central retinal vein occlusion and detached retina following trabeculectomy were coincidental rather than the result of the operation.

\section{Conclusions}

Trabeculectomy was an effective means of lowering the intraocular pressure to less than $21 \mathrm{mmHg}$ in
$80.7 \%$ of the eyes being studied. The reduction in visual acuity following trabeculectomy was due to lens opacities. In those cases which were 'operative failures' a postoperative hyphaema was present for 5 days in $50 \%$, and it seems likely that organisation of the hyphaema blocked the fistula.

I thank Mr P. L. Blaxter, consultant ophthalmic surgeon, for allowing me to see his patients and thus enabling me to prepare this report; $\mathrm{Mr}$ W. G. Coddington, consultant ophthalmic surgeon, for his invaluable help and advice in writing the paper; Mrs J. B. Trinick for her secretarial assistance; and the Medical Records Department for the collection of data.

\section{References}

${ }^{1}$ Cairns JE. Trabeculectomy: Preliminary report of a new method. Am J Ophthalmol 1968; 66: 673-9.

${ }^{2}$ Welsh NH. Failure of filtration operations in the Africans. Br J Ophthalmol 1970; 54: 594-8.

${ }^{3}$ Smith RJH. A new technique for opening the canal of Schlemm. Br J Ophthalmol 1960; 44: 370-3.

${ }^{4}$ Allen L, Burian HM. Trabeculectomy ab externo. Am J Ophthalmol 1962; 53: 19-26.

${ }^{5}$ Harms H, Danheim R. Epicrital consideration of 300 cases of trabeculectomy 'ab externo'. Trans Ophthalmol Soc UK $1969 ; 89$ : 491-9.

${ }^{6}$ Krasnov MM. External fistulization of Schlemms's canal (sinusotomy). Br J Ophthalmol 1968; 52: 157-61.

'Watson PG. Discussion on trabeculectomy for the treatment of open-angle glaucoma. Trans Ophthalmol Soc UK $1969 ; 89$ : 523-6.

${ }^{8}$ Thyer HM, Wilson P. Trabeculectomy. Br J Ophthalmol 1972; 56: 37-40.

${ }^{9}$ Ridgway AEA, Rubinstein K, Smith VH. Trabeculectomy -a study of 86 cases, $\mathrm{Br} J$ Ophthalmol 1972; 56: 511-6.

${ }^{10}$ Ridgway AEA. Trabeculectomy-a follow-up study. Br J Ophthalmol 1974; 58: 680-6.

${ }^{11}$ Welsh NH. Trabeculectomy with fistula formation in the African. Br J Ophthalmol 1972; 56: 32-6.

${ }^{12}$ Freedman J, Shen J, Ahrens M. Trabeculectomy in a Black African glaucoma population. $\mathrm{Br} J$ Ophthalmol 1976; 60: 573-4.

${ }^{13}$ Jerdnal T, Kriisa V. Results of trabeculectomy for pseudoexfoliative glaucoma. A study of 52 cases. Br J Ophthalmol 1974; 58: 927-30.

${ }^{14}$ Smith SJH. The surgical treatment of open-angle glaucoma in Nigeria. Br J Ophthalmol 1978; 62: 283-6. 